
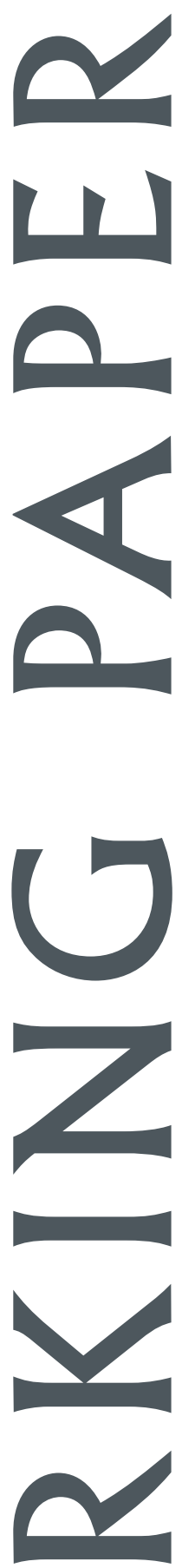

EAST-WEST CENTER 
The U.S. Congress established the East-West Center in 1960 to foster mutual understanding and cooperation among the governments and peoples of the Asia Pacific region including the United States. Funding for the Center comes from the U.S. government with additional support provided by private agencies, individuals, corporations, and Asian and Pacific governments.

East-West Center Working Papers are circulated for comment and to inform interested colleagues about work in progress at the Center.

For more information about the Center or to order publications, contact:

Publication Sales Office

East-West Center

1601 East-West Road

Honolulu, Hawaii 96848-1601

Telephone: 808-944-7145

Facsimile: 808-944-7376

Email: ewcbooks@EastWestCenter.org

Website: www.EastWestCenter.org 


\title{
Why Did the Energy Intensity Fall in China's Industrial Sector in the 1990s? The Relative Importance of Structural Change and Intensity Change
}

\author{
ZhongXiang Zhang
}

ZhongXiang Zhang is a Fellow in the Research Program at the East-West Center. He also is a part-time professor of economics at both the Chinese Academy of Social Sciences and Peking University, Beijing. He is the author of The Economics of Energy Policy in China: Implications for Global Climate Change (Edward Elgar, 1998) and co-author of International Rules for Greenhouse Gas Emissions Trading (United Nations, 1999). Currently, he is serving on the editorial boards of six international journals and one Chinese journal. He has also served as an expert/consultant to many national and international organizations. He has presented research findings in more than 25 countries over the past six years, and has been included in Marquis Who's Who in Science and Engineering and Who's Who in the World.

East-West Center Working Papers: Environment Series is an unreviewed and unedited prepublication series reporting on research in progress. The views expressed are those of the authors and not necessarily those of the Center. Please direct orders and requests to the East-West Center's Publication Sales Office. The price for Working Papers is $\$ 3.00$ each plus postage. To destinations within the U.S. and its territories: for surface mail, add $\$ 3.00$ for the first paper plus $\$ 0.75$ for each additional title or copy sent in the same shipment; for airmail add $\$ 4.00$ for the first paper plus $\$ 1.25$ for each additional title or copy in the same shipment. To destinations elsewhere: for surface mail, add $\$ 6.00$ for the first paper plus $\$ 1.50$ for each additional title or copy sent in the same shipment; for airmail, add $\$ 7.50$ for the first paper plus $\$ 3.50$ for each additional title or copy in the same shipment. 
Why Did the Energy Intensity Fall in China's Industrial Sector in the 1990s?

The Relative Importance of Structural Change and Intensity Change

\author{
ZhongXiang Zhang ${ }^{*}$ \\ Research Program \\ East-West Center \\ 1601 East-West Road \\ Honolulu, HI 96848-1601, USA \\ Tel: +1-808-944 7265 \\ Fax:+1-808-944 7298 \\ Email: ZhangZ@EastWestCenter.org
}

\footnotetext{
* Fellow, Research Program, East-West Center, Honolulu, USA; Part-time Professor of Economics, at both Centre for Environment and Development, Chinese Academy of Social Sciences, Beijing, China and China Centre for Regional Economic Research, Peking University, Beijing, China.
} 


\begin{abstract}
There have been a variety of studies investigating the relative importance of structural change and real intensity change to the change in China's energy consumption in the 1980s. However, no detailed analysis to date has been done to examine whether or not the increased energy efficiency trend in the 1980s still prevailed in the 1990s. This article has filled this gap by investigating the change in energy consumption in China's industrial sector in the 1990s, based on the data sets of value added and end-use energy consumption for the 29 industrial subsectors and using the newly proposed decomposition method of giving no residual. Our results clearly show that the overwhelming contributor to the decline in industrial energy use in the 1990s was the decline in real energy intensity, indicating that the trend of real energy intensity declines in the 1980s at the 2-digit level was still maintained in the 1990s. This conclusion still holds even if we lower the growth rate dramatically in line with the belief that the growth rate of China's GDP may be overestimated.
\end{abstract}

JEL classification: Q43; Q48

Keywords: China, energy, structural change, energy intensity change 


\section{Introduction}

Since launching its open-door policy and economic reform in late 1978, China has experienced spectacular economic growth, with its gross domestic product (GDP) growing at the average annual rate of about $9.7 \%$ over the period $1980-2000$. In the meantime, by implementing a series of policies and measures towards energy conservation (Zhang, 2000), China has cut its energy consumption per unit of GDP by about three quarters since 1980 (or in half since 1990) (see Figure 1). This achievement corresponds to an income elasticity of energy consumption of 0.34 and to an annual saving rate of 5.25\% (Calculated based on the data from State Statistical Bureau (2002)). As shown in Table 1, most developing countries at China's income level have the income elasticity of energy consumption well above one, suggesting that their energy consumption grows much faster than does the GDP. ${ }^{1}$ This clearly indicates that China's achievement is rarely accomplished in countries at this level of development.

Table 1

Growth rates of GDP and energy consumption, and the income elasticity of energy consumption among different economies, 1980-1994

\begin{tabular}{lccc}
\hline & $\begin{array}{c}\text { Annual growth } \\
\text { of GDP (\%) }\end{array}$ & $\begin{array}{c}\text { Annual growth of } \\
\text { energy consumption (\%) }\end{array}$ & $\begin{array}{c}\text { Income elasticity of } \\
\text { energy consumption }\end{array}$ \\
\hline Low-income economies ${ }^{*}$ & 2.5 & 3.3 & 1.32 \\
China & 11.0 & 4.5 & 0.41 \\
India & 5.2 & 6.3 & 1.21 \\
Upper-middle-income economies & 2.5 & 3.9 & 1.56 \\
High-income economies & 2.8 & 1.1 & 0.39 \\
\hline
\end{tabular}

* Excluding China and India.

Source: Zhang (2000).

\footnotetext{
${ }^{1}$ The income elasticity of energy consumption is defined as the change in energy consumption divided by the change in economic growth. As shown in Table 1, the income elasticity of energy consumption in China is quite low by international standards. In addition to energy conservation, there might be other three possible explanations. First, the growth rate of China's GDP is overestimated, as discussed in the later section. Second, the growth of energy consumption is underestimated. China's primary energy production and consumption statistics are usually revised in the year after their first appearance. In the widely publicized nationwide campaign to close down small coal mines, it is likely that even the revised coal production statistics may undercount actual coal output, thus leading to not fully counting the "missing supply" in China's statistics on coal consumption as a result of re-opening the closed mines (Sinton, 2001; U.S. Embassy in China, 2001). Third, quantitative restrictions have kept energy consumption from rising as would otherwise have occurred (Zhang, 2000). Drawing on the analysis of rationing by Neary and Roberts (1980), the quantitative restrictions act like an implicit energy tax levied at rates varying with use and fuel. Generally speaking, households face a higher implicit tax than industrial users, and oil and natural gas are taxed at a higher rate than coal.
} 


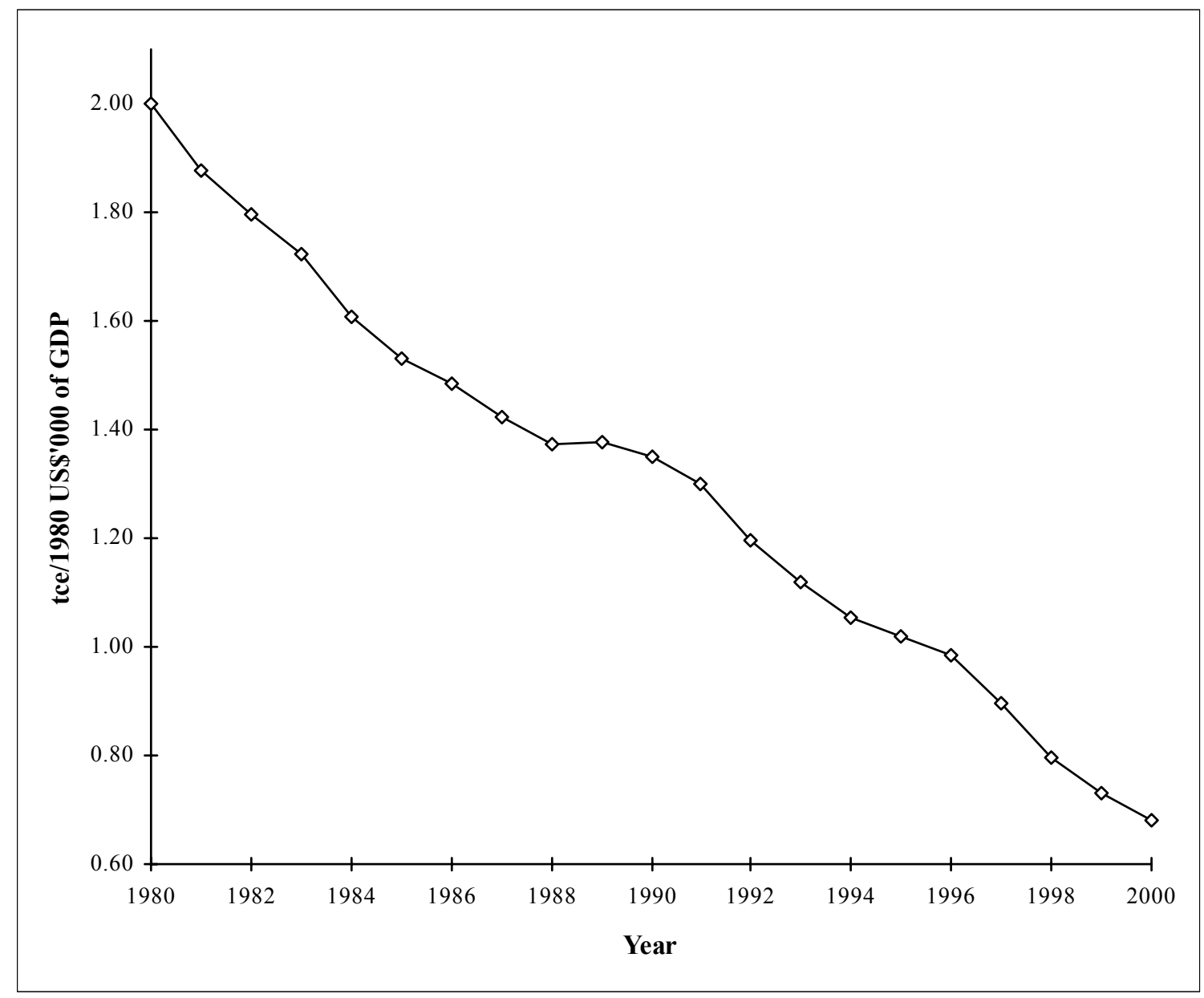

Figure 1

Energy intensity of China's GDP measured in tons of coal equivalent (tce) per US\$ 1000 in 1980 prices Sources: Drawn based on the data from State Statistical Bureau (1992, 1998b, 2002).

The question then arises of what are the causes of this fall in energy use. Published work on this topic has expressed dissenting views. Based on the input-output tables in 1981 and 1987 for China, Lin and Polenske (1995) conducted a structural decomposition analysis to explain China's energy use changes between 1981 and 1987. They found that, relative to 1981, all the energy savings in China in 1987 can be attributed to energy efficiency improvements. Based on China's input-output tables in 1987 and 1992 and using the procedure similar to that used by Lin and Polenske, Garbaccio et al. (1999) concluded that the fall in energy use during 1987-92 was due mostly to a fall in real energy intensity. Using a Laspeyres decomposition method and based on three different sets of energy consumption and gross output value data, Sinton and Levine (1994) examined the relative roles of structural shift and real intensity change in 
China's industrial sector between 1980 and 1990 . They found that real intensity change accounted for $85 \%$ of the country's overall industrial intensity change for the period 1980-90. In contrast with the above studies suggesting that such a fall in energy use has been attributed mainly to the decline in real energy intensity, Smil (1990) and Kambara (1992) have argued that structural shifts away from more energyintensive industrial subsectors to less energy-intensive industrial ones have been the major causal factor.

To ascertain the relative importance of structural change and intensity change is important not only because it provides policy makers with the energy impact of the policies that have been implemented, but also because a good understanding of this issue helps to improve the credibility of future projections for energy demand and energy-related emissions. This article aims to examine this disagreement by investigating the relative importance of structural change and real intensity change to the change in energy consumption in China's industrial sector. There are at least two reasons for choosing the industrial sector for our study. First, in China, industry is the dominant energy-consuming sector. As shown in Figure 2, although on average $40.6 \%$ of China's GDP originated from the industrial sector from 1990 to 2000, it accounted for as high as $67.8 \%$ of the country's total end-use energy consumption. Because the industrial sector is critical for the past and future energy consumption, a deeper understanding of how energy consumption evolves in the sector is very important in formulating future policy. Second, the data at fine level of disaggregation are available for the sector. This makes it possible to calculate how much of the fall in the total industrial energy use is due to structural shifts within the subsectors and how much to changes in real energy intensity.

This study differs from previous analyses in two important aspects. First, previous work examined the relative contributions of structural change and real intensity change to energy savings in the 1980s or between 1987 and 1992, while our study examines their relative importance in the 1990s to see whether or not the increased energy efficiency trend in the 1980s still prevailed in the 1990s. Second, we have proposed a decomposition method different from the Laspeyres method or Divisia method commonly used by previous work. This proposed method gives no residual so that all of the observed change in industrial energy consumption can be explained. 


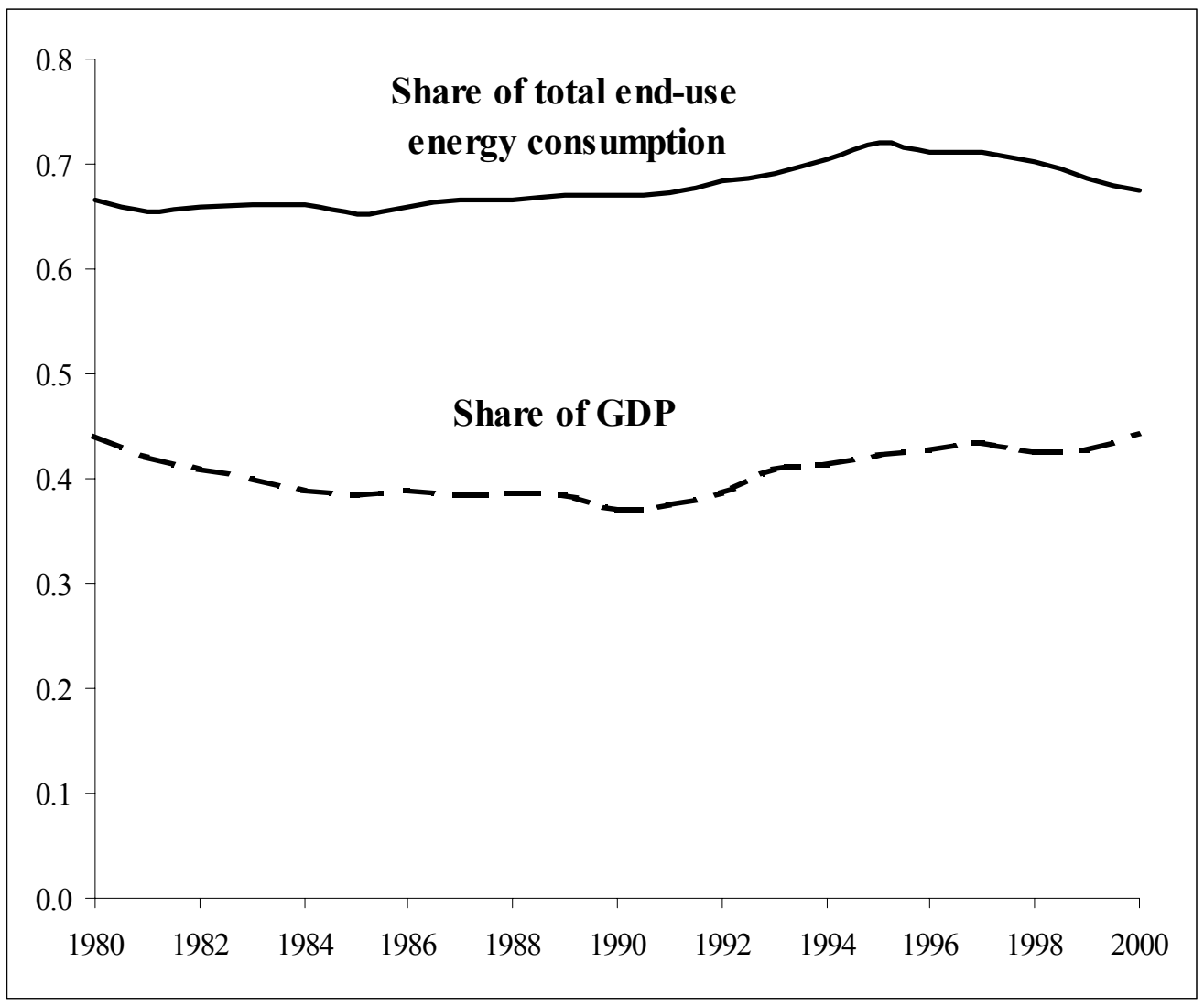

Figure 2

Shares of the industrial sector in China's GDP and total end-use energy consumption Sources: Drawn based on the data from State Statistical Bureau (1992, 1998b, 2001, 2002).

This article is organised as follows. Section 2 describes the method to decompose the contributions of economic growth, structural change and real intensity change to the change in total energy consumption. Section 3 discusses the data used. Section 4 applies the decomposition method to analyse the changes in energy consumption in China's industrial sector from 1990 to 1997 and presents the results from such a analysis. Section 5 tests the sensitivity of the results to the adjustment of the output data. Finally, Section 6 offers concluding remarks.

\section{Decomposition method}


Let $E_{o}$ and $E_{t}$ be total energy consumption in the industrial sector in year $o$ and year $t$. The change in total industrial energy consumption between the two years, $\Delta E_{t o t}=E_{t}-E_{o}$, is decomposed as follows:

$$
\Delta E_{\text {tot }}=\Delta E_{\text {out }}+\Delta E_{\text {str }}+\Delta E_{\mathrm{int}}+R
$$

The first term $\Delta E_{\text {out }}$ on the right-hand side represents a change in energy consumption due to a change in aggregate production (output effect). The second term $\Delta E_{\text {str }}$ represents a change in energy consumption due to changes in composition of aggregate production (structural effect). If less energyintensive industrial subsectors grow faster than do more energy-intensive industrial ones, such a structural change will put the downward pressure on energy demand, thus resulting in lower growth rate of energy consumption than would otherwise have been the case. The third term $\Delta E_{\text {int }}$ shows a change in energy consumption due to changes in subsectoral energy intensities (intensity effect). Real energy intensity may decline as a result of the adoption of more efficient production technologies and energy management techniques, changes in product mix within and between subsectors, changes in product value as well as changes in the quality and mix of material and fuel inputs. This is the reason why we refer this effect to the intensity effect rather than the technological effect because it contains more than purely technological changes. The last term is a residual.

In decomposing the change in overall energy consumption, the Laspeyres method has been used extensively. ${ }^{2}$ Proposed by Park (1992), the method calculates changes in energy consumption with respect to a constant base year and has the following components:

$$
\begin{gathered}
\Delta E_{\text {out }}=\sum_{i} Q_{t} s_{i, o} I_{i, o}-E_{o}=\left(Q_{t}-Q_{o}\right) \sum_{i} s_{i, o} I_{i, o} \\
\Delta E_{s t r}=\sum_{i} Q_{o} s_{i, t} I_{i, t}-E_{o}=Q_{o} \sum_{i}\left(s_{i, t}-s_{i, o}\right) I_{i, o}
\end{gathered}
$$

${ }^{2}$ The Laspeyres method and Divisia method are the two most commonly used decomposition methods. Studies that employed either of the two methods include Ang and Lee (1994), Boyd et al. (1987), Boyd et al. (1988), Howarth et al. (1991), and Liu et al. (1992). Howarth et al. (1991) show that the two methods of decomposing manufacturing energy use in eight OECD countries yield very similar results in terms of the relative importance of the driving force of aggregate energy intensity declines. 


$$
\Delta E_{\mathrm{int}}=\sum_{i} Q_{o} s_{i, o} I_{i, t}-E_{o}=Q_{o} \sum_{i} s_{i, o}\left(I_{i, t}-I_{i, o}\right)
$$

where $Q_{o}$ and $Q_{t}$ are aggregate production in the industrial sector in year $o$ and year $t, s_{i, o}$ and $s_{i, t}$ are the $i$ th industrial subsector's share of aggregate production in year $o$ and year $t$, and $I_{i, o}$ and $I_{i, t}$ are energy intensity in each industrial subsector $i$ in year $o$ and year $t$.

The Laspeyres method is more easily interpreted. But the disadvantage of the method is that there is a residual, which is not equal to zero and generally increases as $t$ increases (Howarth et al., 1991). This leaves part of the observed change in industrial energy consumption unexplained. For this reason, we propose a different decomposition method. By keeping the definition of the first term unchanged but redefining the last two terms, this proposed method is as easily interpreted as the Laspeyres method, but gives no residual.

In what follows, we start describing the proposed method by defining $\Delta E_{s t r}$ to represent a difference between what energy consumption would have been if each subsectoral output at year $t$ had been produced at the energy intensity of year $o$ and that if the aggregate production at year $t$ had been composed in the same way at year $t$ as at year $o$ and had been produced at the energy intensity of year $o$. Define $\Delta E_{\text {int }}$ to represent a difference between the observed energy consumption and what energy consumption would have been if each subsectoral output at year $t$ had been produced at the energy intensity of year $o$. Thus, we have

$$
\begin{aligned}
& \Delta E_{\text {str }}=\sum_{i}\left(Q_{t} s_{i, t} I_{i, o}-Q_{t} s_{i, o} I_{i, o}\right)=Q_{t} \sum_{i}\left(s_{i, t}-s_{i, o}\right) I_{i, o} \\
& \Delta E_{\mathrm{int}}=\sum_{i}\left(Q_{t} s_{i, t} I_{i, t}-Q_{t} s_{i, t} I_{i, o}\right)=Q_{t} \sum_{i} s_{i, t}\left(I_{i, t}-I_{i, o}\right)
\end{aligned}
$$

The proposed decomposition method gives no residual on the right-hand side. This can be illustrated as follows. Summing over the three terms, we have 


$$
\begin{aligned}
& \Delta E_{\text {out }}+\Delta E_{s t r}+\Delta E_{\mathrm{int}} \\
& =\left(Q_{t}-Q_{o}\right) \sum_{i} s_{i, o} I_{i, o}+Q_{t} \sum_{i}\left(s_{i, t}-s_{i, o}\right) I_{i, o}+Q_{t} \sum_{i} s_{i, t}\left(I_{i, t}-I_{i, o}\right) \\
& =Q_{t} \sum_{i} s_{i, o} I_{i, o}-Q_{o} \sum_{i} s_{i, o} I_{i, o}+Q_{t} \sum_{i} s_{i, t} I_{i, o}-Q_{t} \sum_{i} s_{i, o} I_{i, o}+Q_{t} \sum_{i} s_{i, t} I_{i, t}-Q_{t} \sum_{i} s_{i, t} I_{i, o} \\
& =-Q_{o} \sum_{i} s_{i, o} I_{i, o}+Q_{t} \sum_{i} s_{i, t} I_{i, t}=-E_{o}+E_{t}=\Delta E_{t o t}
\end{aligned}
$$

\section{Sector disaggregation and data}

The choice for a level of sector disaggregation is mainly dictated by the purpose of analysis and data availability. Ideally, the fine level of subsectoral detail is desirable in order to accurately disentangle the structural effect from the intensity effect. Sinton and Levine (1994) shows that as the level of subsectoral detail becomes finer, more intensity change becomes attributable to structural shift. Given that the effect of changes in product mix within and between subsectors is counted as the intensity effect, this should thus come as no surprise because a finer level of sector disaggregation is able to more accurately separate the effect from the intensity effect. But, in practice, the desire for a finer level of sector disaggregation is often restrained by data availability. This is certainly the case in China where the data for industrial value added and energy use are at roughly the 2-digit industry classification level.

Unlike Huang (1993) and Sinton and Levine (1994) where gross output value is used as the output indicator, value added is used as the output indicator for this present study in order to avoid double accounting the value of intermediate goods. ${ }^{3}$ The data for value added in the industrial sector are disaggregated into 40 subsectors for the period 1991-92 and into 39 subsectors in 1999, the latest year in which detailed end-use energy consumption data in a consistent manner are available. The data for end-use energy consumption are disaggregated into 31 subsectors for the period 1991-96 and into 39 subsectors for

\footnotetext{
${ }^{3}$ Gross output value measures all the output of the economy, regardless of to whom it is sold. Gross output value includes significant double accounting, because it reports output at every stage of production. For example, rubber is reported not only as rubber output, but also as part of tire output. It is again reported as part of bicycle output. There are two ways to avoid this double accounting in national accounts. One way is to measure value added to calculate only the new value that is added to the materials and services purchased as inputs. Another way is to measure final expenditures by reporting only what is ultimately sold
} 
the period 1997-99. For each subsector, the total end-use energy consumption is the sum of the standard coal equivalents of coal, oil, natural gas, hydropower and nuclear power consumed. Because the energy consumption data are not compatible with such an industrial subsector classification, reconciling the differences between the two data sets obliges us to disaggregate the industrial sector into 29 subsectors.

For the years from 1991 to 1997 , the data for value added at current prices for all independent accounting units at or above the township level in the industrial sector are collected and reported in the Chinese statistical yearbook. But from 1998 onwards, the data for value added at current prices are reported for all state-owned industrial enterprises plus the non-state-owned industrial enterprises with an annual sales revenue of over 5 million yuan (about US\$ 0.6 million). ${ }^{4}$ This change in the scope of enterprises covered in industrial statistics makes the data set for 1991-97 incomparable with the data set for 1998-99. To be consistent in data set, we are forced to only cover the period 1991-97 for our comparative data analysis. The corresponding yearly data for value added at current prices and energy consumption in each subsector are taken from the Chinese State Statistical Bureau (1993, 1994, 1995, 1996, 1998a, 1998b, 2001).

In this study, we use 1991 as the base year. Price indices from 1991 to 1997 are disaggregated into 14 subsectors and are derived from the Chinese State Statistical Bureau (1998c). Because price indices are less disaggregated than the value added data, in converting 29-subsector value added at current prices into that in 1990 constant prices, the same price index is thus used for those subsectors that are further disaggregated from the same higher-level subsector.

for household consumption, government consumption, new investment and net sales to the rest of the world. In principle, these two methods should lead to the same accounting results (Keidel, 2001).

${ }^{4}$ One of the major changes in industrial statistics since 1998 has been the switch from compiling detailed statistics on enterprises identified by an administrative criterion (located at or above the township level) to enterprises that exceed a fixed volume of sales revenue. This change makes it impossible to construct comparable time series data in the industrial sector using officially published industrial statistics. In addition, such a change into the size criterion has at least three implications. First, although all state-owned enterprises (SOEs) with independent accounting units are still included, non-SOEs with independent accounting units at or above the township level but with sales revenue of less than 5 million yuan are now excluded from the detailed industrial statistics. In the meantime, enterprises at the village level that meet the two requirements are now included. Second, all self-employed individuals, who were previously excluded from the detailed statistics through the administrative criterion, are now explicitly excluded, regardless of their size. Third, given that those enterprises included through the size criterion are likely to have trained accountants and more reliable bookkeeping, the change in the scope of coverage may improve the accuracy and reliability of the data collected and reported (Holz and Lin, 2001). 


\section{The relative importance of structural change and intensity change}

In this section, we will apply the above proposed decomposition method to analyse the changes in energy consumption in China's industrial sector from 1990 to 1997.

In the 1990s, the industrial sector experienced spectacular growth. Accompanying the growth, the cumulative energy consumption in the industrial sector between 1991 and 1997 would increase by 2147.03 million tons of coal equivalent (Mtce), as shown in Table 2, provided that the production structure and energy intensity had remained unchanged. But, the actual cumulative energy consumption in the industrial sector during the period increased only by 1066.58 Mtce. Clearly, it is energy conservation that pushed the energy consumption during the period under review downward. Measured as the difference between the would-be and actual energy consumption, the accumulative energy savings between 1991 and 1997 amounted to 1080.45 Mtce.

Table 2

Changes in the cumulative industrial energy consumption from 1990 to 1997 (Mtce) ${ }^{\mathrm{a}}$

\begin{tabular}{cccc}
\hline $\begin{array}{l}\text { Due to change in } \\
\text { aggregate production }\end{array}$ & $\begin{array}{l}\text { Due to change in } \\
\text { production structure }\end{array}$ & $\begin{array}{l}\text { Due to change in } \\
\text { energy intensity }\end{array}$ & $\begin{array}{l}\text { Actual change in } \\
\text { cumulative energy } \\
\text { consumption }\end{array}$ \\
\hline+2147.03 & -132.16 & -948.29 & +1066.58 \\
\hline
\end{tabular}

${ }^{\text {a }}$ A positive sign indicates an increase in energy consumption; a negative sign indicates a decline.

With respect to the breakdown of the contributions, our results show that 948.29 Mtce or $87.8 \%$ of the cumulative industrial energy savings for the period 1990-97 were attributed to real intensity change. Because this study and the above cited studies for the 1980s all use data at roughly the 2-digit industry classification level, this dominant role of intensity change clearly indicates that the trend of real energy intensity declines in the 1980s at the 2-digit level was still maintained in the 1990s.

Figure 3 shows the results in more subsectoral detail. The lengths of the bars are in proportion to changes in cumulative energy consumption by each industrial subsector, with a negative sign indicating the contributions to energy savings and a positive sign indicating the increase in energy consumption. 


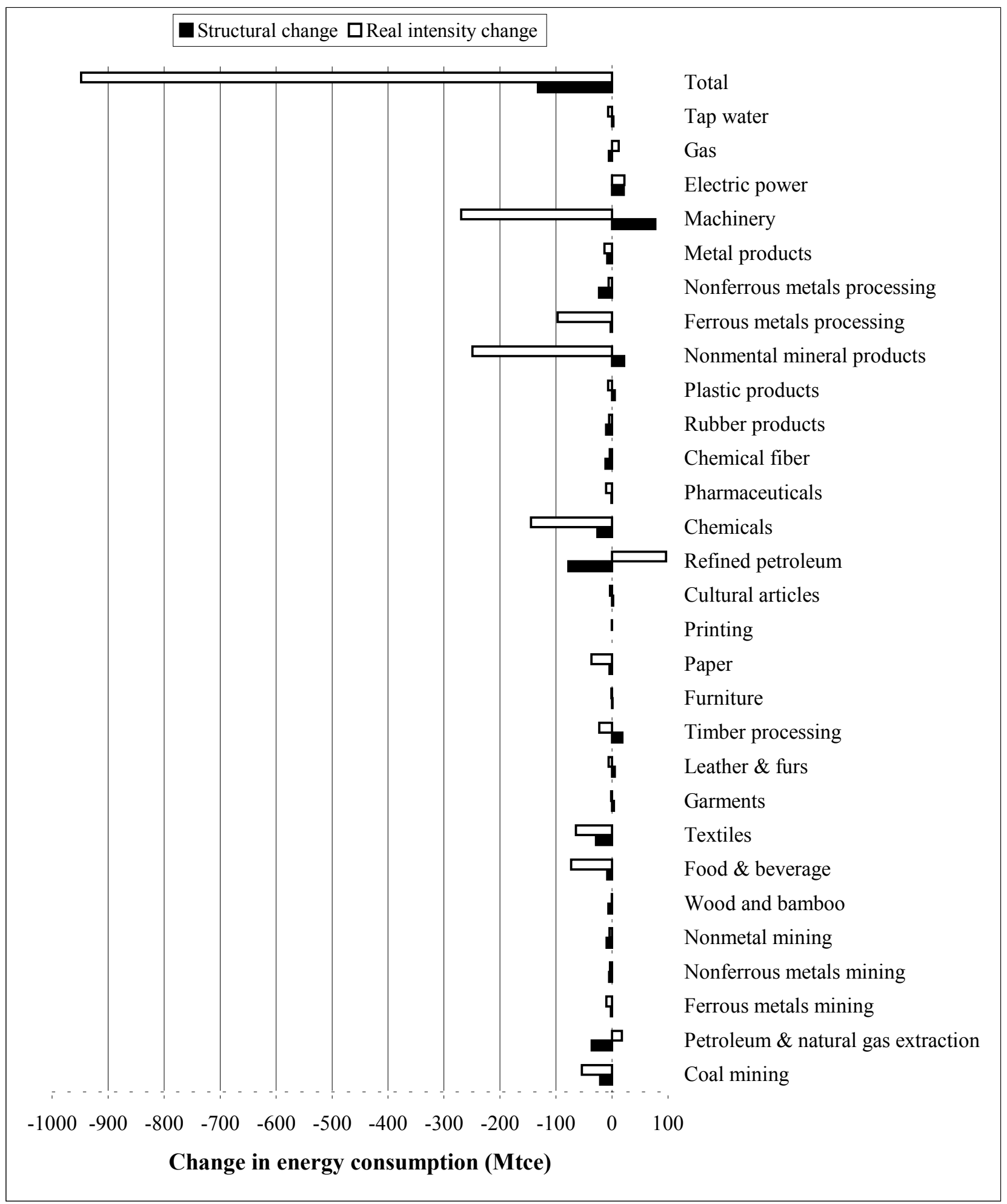

Figure 3

Changes in cumulative end-use energy consumption by each industrial subsector from 1991 to 1997 
Table 3

Each industrial subsector's shares of total value added and cumulative end-use energy consumption from 1991 to 1997

\begin{tabular}{lcc}
\hline & $\begin{array}{l}\text { Average share } \\
\text { of total } \\
\text { industrial } \\
\text { value added } \\
(\%)\end{array}$ & $\begin{array}{l}\text { Share of } \\
\text { cumulative } \\
\text { end-use energy } \\
\text { consumption } \\
(\%)\end{array}$ \\
\hline Coal mining and dressing & 3.43 & 4.06 \\
Petroleum and natural gas extraction & 5.08 & 2.98 \\
Ferrous metals mining and dressing & 0.29 & 0.39 \\
Nonferrous metals mining and dressing & 0.66 & 0.59 \\
Nonmetal and other minerals mining and dressing & 0.97 & 0.71 \\
Logging and transport of wood and bamboo & 0.65 & 0.27 \\
Food, beverage and tobacco processing & 11.54 & 4.84 \\
Textile industry & 6.84 & 4.04 \\
Garments and other fiber products & 2.29 & 0.31 \\
Leather, furs, down and related products & 1.23 & 0.26 \\
Timber processing, bamboo, cane, palm \& straw products & 0.66 & 0.42 \\
Furniture manufacturing & 0.40 & 0.14 \\
Papermaking and paper products & 1.52 & 2.43 \\
Printing and record medium reproduction & 0.92 & 0.21 \\
Cultural, educational and sports articles & 0.57 & 0.09 \\
Petroleum processing and coking & 3.03 & 4.37 \\
Raw chemical materials and chemical products & 6.17 & 18.38 \\
Medical and pharmaceutical products & 1.94 & 1.14 \\
Chemical fiber & 1.27 & 1.33 \\
Rubber products & 1.11 & 0.77 \\
Plastic products & 1.64 & 0.64 \\
Nonmental mineral products & 6.11 & 14.78 \\
Smelting and pressing of ferrous metals & 7.18 & 18.60 \\
Smelting and pressing of nonferrous metals & 1.82 & 3.26 \\
Metal products & 2.72 & 1.19 \\
Machinery, electric equipment, electronic \& other manufacturing & 22.96 & 8.10 \\
Electric power, steam and hot water production and supply & 6.42 & 4.94 \\
Gas production and supply & 0.07 & 0.25 \\
Tap water production and supply & 0.50 & 0.54 \\
\hline
\end{tabular}

Sources: Calculated based on the data from State Statistical Bureau (1993, 1994, 1995, 1996, 1998a, 1998b, 1998c, 2001).

As shown in Table 3, within the industrial sector, the chief energy using subsectors are ferrous metals, chemicals, nonmental mineral products, and machinery. Between 1991 to 1997, the four subsectors consumed $18.6 \%, 18.4 \%, 14.8 \%$ and $8.1 \%(59.9 \%$ in total) of the total end-use energy consumption in the industrial sector, respectively. From Figure 3, it can be seen that the machinery subsector exhibited the greatest reduction in energy consumption, accounting for $28.4 \%$ of the total reduction in industrial energy consumption due to decline in real energy intensity during the period 1991-97. Such a reduction is a result of the combined effects of decline in real energy intensity and the largest share ( $23 \%$ on average) of the 
subsector in the total industrial output (see Table 3). This is followed by the nonmental mineral products, chemicals, and ferrous metals subsectors. Real intensity declines in the last three subsectors contributed to $26.3 \%, 15.3 \%$ and $10.2 \%$ of the above total reduction. With $80.2 \%$ of the total occurring in the four subsectors, it is fair to say that real intensity declines in the four subsectors had kept industrial energy consumption from rising to 2147.03 Mtce as would otherwise have occurred.

\section{The effects of an alternative lower growth rate}

The credibility of China's statistics on economic growth has been an issue of concern for decades. It has been widely argued that China's statistical authorities underestimate China's GDP level and thus overestimate the GDP growth rate. Using a measurement technique closer to Western national accounting practice, Maddison (1997), for example, re-estimates China's GDP. He found that during the period 19521978 China's GDP grew at an average annual rate of $4.4 \%$, in comparison with the official rate of $6 \%$. For the period 1978-1994, his estimate for the GDP growth rate is $7.4 \%$, whereas the official growth figure is 9.8\%. With China's statistical system switching from the Soviet Material Product System to the System of National Accounts in the late 1980s and early 1990s, the officially reported growth rate of GDP is expected to be close to the real growth rate. But some analysts (e.g., Rawski, 2001) have argued that the official growth rates in the 1990 s even further deviated from the real growth rates. For example, Wang and Meng (2001) found that China's official GDP growth rate may have been overstated by $3.2 \%$ for the period 1992 97, in comparison with the overstatement amounting to $1.3 \%$ for the period 1978-1991. Although the technical difficulties in statistical practices have played a part, they have argued the widespread falsification and exaggeration have been the major causal factor. On the other hand, in the recent interviews with Dr. Xu Xianchun ${ }^{5}$ and Prof. Ren Ruoen, ${ }^{6}$ the two authoritative persons, respectively inside and outside the National Bureau of Statistics, have defended that China's GDP statistics basically reflect the real

\footnotetext{
5 “Are China's GDP Statistics Credible? Interview with Xu Xianchun at the National Bureau of Statistics", Southern Weekends, 1 August 2002, Available at http://finance.sina.com.cn/g/20020801/1206239196.html. 6 "The Authoritative Scholar Questions: Are Rawski's Assumptions about China's GDP Rational?", Financial Times, 14 May 2002, Available at http://finance.sina.com.cn/g/20020514/206472.html.
} 
situation of economic development, although they recognize the need to further improve the present statistical system.

To test the sensitivity of the above results to the output value, we lower the annual growth rate of GDP by 2\% from 1991 to 1997 . Provided that its share in GDP remains unchanged, the annual growth rate of each industrial subsector accordingly reduces by $2 \% .^{7}$ As would be expected from the assumed slow down of economic growth, the cumulative increases in energy consumption in the industrial sector between 1991 and 1997 would drop from 2147.03 Mtce in the above case of the high GDP growth rate to 1721.59 Mtce, as given in Table 4. Given the fact that the actual cumulative energy consumption in the industrial sector during the period remained unchanged, this implies that, in absolute terms, the cumulative contribution of energy conservation, which amounted to 655.01 Mtce, would be less than 1080.45 Mtce in the above case of the high GDP growth rate. In percentage terms, however, $82.1 \%$ of the cumulative energy savings in the industrial sector for the period 1990-97 were attributed to real intensity change. This clearly indicates that our above finding on the relative importance of structural change and real intensity change to the change in energy consumption in China's industrial sector is fairly robust to the adjustment of the output data.

Table 4

Changes in the cumulative industrial energy consumption associated with a lower GDP growth rate from 1990 to 1997 (Mtce) $^{\mathrm{a}}$

\begin{tabular}{cccc}
\hline $\begin{array}{l}\text { Due to change in } \\
\text { aggregate production }\end{array}$ & $\begin{array}{l}\text { Due to change in } \\
\text { production structure }\end{array}$ & $\begin{array}{l}\text { Due to change in } \\
\text { energy intensity }\end{array}$ & $\begin{array}{l}\text { Actual change in } \\
\text { cumulative energy } \\
\text { consumption }\end{array}$ \\
\hline+1721.59 & -117.47 & -537.54 & +1066.58 \\
\hline
\end{tabular}

${ }^{a}$ A positive sign indicates an increase in energy consumption; a negative sign indicates a decline.

\section{Conclusions}

\footnotetext{
${ }^{7}$ There is a wide suspicion that the official rate of inflation for producer prices is understated because the official prices might not be the properly weighted average of plan and market prices, might have been misreported, or were not produced using a good sample of firms (Rawski, 1991; Garbaccio et al., 1999). Assuming that the official data for GDP and industrial subsector value added are correct, lowering the annual growth rate of each industrial subsector by $2 \%$ is equivalent to raising the annual rate of inflation of all industrial products by the same percentage in terms of the impacts on the energy consumption, although the reasons for the two adjustments are very different from each other.
} 
By implementing a series of policies and measures towards energy conservation, China has cut its energy consumption per unit of GDP by about three quarters since 1980 (or in half since 1990). In the literature of examining the causes of this fall in energy use in the 1980s, however, there seems to be dissenting view. Some analysts believe that such a fall has been attributed mainly to the decline in real energy intensity, whereas others think that structural shifts away from more energy-intensive industrial subsectors to less energy-intensive industrial ones have been the major causal factor.

Based on the data sets of value added and end-use energy consumption for the 29 industrial subsectors and using our proposed decomposition method of giving no residual, we have examined this disagreement by investigating the relative importance of structural change and real intensity change to the change in energy consumption in China's industrial sector in the 1990s. Our results show that $88 \%$ of the cumulative energy savings in the industrial sector for the period 1990-97 were attributed to real intensity change, with about $80 \%$ of such savings from the four chief energy using subsectors (i.e., ferrous metals, chemicals, nonmental mineral products and machinery). Because this study and the cited studies for the 1980s all use data at roughly the 2-digit industry classification level, this dominant role of intensity change clearly indicates that the trend of real energy intensity declines in the 1980s at the 2-digit level was still maintained in the 1990s.

Finally, to test the robustness of the above conclusion, we have lowered the annual growth rate of each industrial subsector by $2 \%$ in line with the belief that the growth rate of China's GDP may be overestimated. It is clear from this sensitivity analysis that our conclusion that the major contributor to the decline in industrial energy use in the 1990s was the decline in real energy intensity does not change even if the growth slows down dramatically.

\section{Acknowledgements}

This article formed part of the presentations at the Joint Meeting of the Energy Modeling Forum and the International Energy Workshop, Stanford University, 20-22 June 2000 and the European Climate 
Forum's Conference on Climate Change and Paths to Sustainability, Berlin, 14-15 November 2002 and at a seminar at the East-West Center, Honolulu, 16 April 2001. The author would like to thank participants in the above meetings and anonymous referees for useful discussions and comments on an earlier version of the article. The views expressed here are those of the author. The author bears sole responsibility for any errors and omissions that may remain.

\section{References}

Ang, B.W. and S.Y. Lee (1994), Decomposition of Industrial Energy Consumption: Some Methodological and Application Issues, Energy Economics, Vol. 16, No. 2, pp. 83-92.

Boyd, G.A., Hanson, D.A. and T. Sterner (1988), Decomposition of Changes in Energy Intensity: A Comparison of the Divisia Index and Other Methods, Energy Economics, Vol. 10, pp. 309-312.

Boyd, G., McDonald, J.F., Ross, M. and D.A. Hanson (1987), Separating the Changing Composition of US Manufacturing Production from Energy Efficiency Improvements: A Divisia Index Approach, Energy Journal, Vol. 8, No. 2, pp. 77-96.

Garbaccio, R.F., Ho, M.S. and D.W. Jorgenson (1999), Why Has the Energy-Output Ratio Fallen in China?, Energy Journal, Vol. 20, No. 3, pp. 63-91.

Holz, C.A. and Y. Lin (2001), The 1997-1998 Break in Industrial Statistics: Facts and Appraisal, China Economic Review, Vol. 12, No. 4, pp. 303-316.

Howarth, R.B., Schipper, L., Duerr, P.A. and S. Strøm (1991), Manufacturing Energy Use in Eight OECD Countries: Decomposing the Impacts of Changes in Output, Industry Structure and Energy Intensity, Energy Economics, Vol. 13, pp. 135-142.

Huang, J.P. (1993), Industrial Energy Use and Structural Change: A Case Study of the People's Republic of China, Energy Economics, Vol. 15, pp. 131-136.

Kambara, T. (1992), The Energy Situation in China, China Quarterly, No. 131, pp. 608-636.

Keidel, A. (2001), China’s GDP Expenditure Accounts, China Economic Review, Vol. 12, No. 4, pp. 355367. 
Lin, X. and K.R. Polenske (1995), Input-Output Anatomy of China's Energy Use Changes in the 1980s, Economic Systems Research, Vol. 7, No. 1, pp. 67-84.

Liu, X.Q., Ang, B.W. and H.L. Ong (1992), The Application of the Divisia Index to the Decomposition of Changes in Industrial Energy Consumption, Energy Journal, Vol. 13, No. 4, pp. 161-177.

Maddison, A. (1997), Measuring Chinese Economic Growth and Levels of Performance, Organisation for Economic Co-operation and Development, Paris.

Neary, J.P. and K.W.S. Roberts (1980), The Theory of Household Behaviour under Rationing, European Economic Review, Vol. 13, pp. 25-42.

Park, S.H. (1992), Decomposition of Industrial Energy Consumption: An Alternative Method, Energy Economics, Vol. 14, pp. 265-270.

Rawski, T. G. (1991), How Fast Has Chinese Industry Grown?, Research Paper Series No. 7, Socialist Economics Reform Unit, Country Economics Department, World Bank, Washington, DC.

Rawski, T. G. (2001), What Is Happening to China's GDP Statistics?, China Economic Review, Vol. 12, No. 4, pp. 347-354.

Sinton, J.E. (2001), Accuracy and Reliability of China's Energy Statistics, China Economic Review, Vol. 12, No. 4, pp. 373-383.

Sinton, J.E. and M.D. Levine (1994), Changing Energy Intensity in Chinese Industry: The Relative Importance of Structural Shift and Intensity Change, Energy Policy, Vol. 22, pp. 239-255.

Smil, V. (1990), China's Energy, Report Prepared for the U.S. Congress, Office of Technology Assessment, Washington, DC.

State Statistical Bureau (1992), China Energy Statistical Yearbook 1991, China Statistical Publishing House, Beijing.

State Statistical Bureau (1993, 1998a), China Industrial Economic Statistical Yearbook, China Statistical Publishing House, Beijing.

State Statistical Bureau (1994, 1995, 1996, 1998c, 2002), China Statistical Yearbook, China Statistical Publishing House, Beijing.

State Statistical Bureau (1998b), China Energy Statistical Yearbook 1991-1996, China Statistics Press, Beijing. 
State Statistical Bureau (2001), China Energy Statistical Yearbook 1997-1999, China Statistical Publishing House, Beijing.

U.S. Embassy in China (2001), Scrutinizing Chinese Energy Statistics, Beijing Environment, Science and Technology Update, The Environment, Science and Technology Section, Beijing, July 27.

Wang, X. and L. Meng (2001), A Reevaluation of China's Economic Growth, China Economic Review, Vol. 12, No. 4, pp. 338-346.

Zhang, Z.X. (2000), Can China Afford to Commit itself an Emissions Cap? An Economic and Political Analysis, Energy Economics, Vol. 22, No. 6, pp. 587-614. 